\title{
Would You Be Happier If You Looked Better? A Focusing Illusion
}

\author{
Lukasz D. Kaczmarek • Jolanta Enko • Małgorzata Awdziejczyk • \\ Natalia Hoffmann • Natalia Białobrzeska · Przemysław Mielniczuk • \\ Stephan U. Dombrowski
}

Published online: 23 November 2014

(C) The Author(s) 2014. This article is published with open access at Springerlink.com

\begin{abstract}
Some people might believe that individuals who are more satisfied with their body are also happier. However, people tend to overrate the influence of some factors (e.g. money or health) on their happiness; a phenomenon termed the focusing illusion. Our aim was to examine the focusing illusion in relation to body satisfaction. We experimentally manipulated body satisfaction and life satisfaction focus by varying the order of relevant measurement scales. Volunteers $(N=97)$ completed two questionnaires placed in separate envelopes to control the order of scales administration. Participants either completed the Body Satisfaction Scale followed by the Satisfaction with Life Scale or vice versa. In line with the focusing illusion the association between body satisfaction and life satisfaction was significantly stronger when participants were asked about their body satisfaction first. Body satisfaction as a focusing illusion may need to be considered by scientist as well as lay people who try to look better and be happier.
\end{abstract}

Keywords Life satisfaction · Body satisfaction · Focusing illusion

\section{Introduction}

Theorists have argued that individuals focused on one aspect of life tend to overestimate its impact on their overall satisfaction with life; a phenomenon termed "focusing illusion" (Schkade and Kahneman 1998). Focusing attention on any aspect of life is thought to amplify its perceived everyday impact, whereas life satisfaction is the resultant of multiple factors such as job satisfaction (Judge and Watanabe 1993), martial happiness (Hawkins

L. D. Kaczmarek $(\square) \cdot$ J. Enko $\cdot$ M. Awdziejczyk $\cdot$ N. Hoffmann $\cdot$ N. Białobrzeska $\cdot$ P. Mielniczuk Institute of Psychology, Adam Mickiewicz University, 89 Szamarzewskiego Street, 60-568 Poznan, Poland e-mail: Lkacz@amu.edu.pl

S. U. Dombrowski

University of Stirling, Stirling, Scotland, UK 
and Booth 2005), neighborhood satisfaction (Shin et al. 2010), or satisfaction with body (Muñoz and Ferguson 2012; Stokes and Frederick-Recascino 2003).

The focusing illusion, however, has not been universally shown for all domains of life. Peoples' daily concerns, values and life tasks for instance have been found to have an enduring rather than illusory influence on personal well-being, suggesting that these factors consistently exert influence on judgments about one's life satisfaction (Oishi et al. 2003). These enduring influence are in contrast to factors that influence well-being judgments only if people focus their attention on them (Kahneman et al. 2006). Moreover, some instances of such partial focusing illusions have been demonstrated. For instance, individuals have been shown to overestimate the impact of poverty on decreases in well-being but their perception for high income remained accurate (Aknin et al. 2009).

As focusing illusions can misguide behavior and important life decisions (Kahneman et al. 2006), it is imperative to understand the life domains where people tend to perceive a skewed impact of a particular factor on their well-being. To date, evidence of the focusing illusion has been found for income (Aknin et al. 2009; Kahneman et al. 2006), dating (Strack et al. 1988), marriage (Schwarz et al. 1991), and health (Smith et al. 2006).

Life satisfaction has been often related to body satisfaction in the literature (Muñoz and Ferguson 2012; Sheldon 2010; Stokes and Frederick-Recascino 2003). The aim of this study was to demonstrate the focusing illusion regarding body satisfaction. We tested whether the influence of body satisfaction on life satisfaction is stronger after facilitating a body satisfaction focus. An experimental design allowed to compare spontaneous ratings of life satisfaction with ratings immediately preceded by an explicit focus on body satisfaction. This approach contributes to the understanding of situational factors that affect life satisfaction ratings.

\section{How Focusing Illusion Works}

Satisfaction with life is by definition a subjective judgment of well-being made by a given individual (Diener et al. 1985). Due to its subjective origin, life satisfaction judgments depend mostly on domains that readily come to mind when one thinks about his or her life, e.g. marriage, health, or occupation (Oishi et al. 2003). Yet, such chronically accessible information can be temporarily suppressed if other information becomes in the focal point of attention at any given time (Strack et al. 1988). The focusing illusion is a particular instance when human judgment is biased because an entire object (life, in this case) is evaluated with attention restricted to a subset of that category (e.g. money). The attended subset is overweighed relative to the unattended subset, which results in deceptive beliefs about its everyday importance.

The focusing illusion has been studied using various methodological approaches. Kahneman et al. (2006) asked participants to report the percentage of time spent in bad mood on the previous day. The participants were also asked to estimate the time spent in bad mood for individuals living in different circumstances (e.g., individuals on low and high income). Individuals generally overestimated the prevalence of bad mood and severely exaggerated predicted bad mood for people with undesirable life circumstances, such as low income. In addition, income was correlated more strongly with global judgment of life satisfaction, compared to daily ratings of happiness.

Aknin et al. (2009) asked participants to report their household income, their own life satisfaction, and to predict the life satisfaction of 10 individuals with various incomes. They compared predicted satisfaction with actual reports of life satisfaction and found that participants overrated dissatisfaction with life among individuals with less income. 
In another experiment (Strack et al. 1988), participants were asked about their global satisfaction with life and about their satisfaction with specific areas of their life, such as romantic relationships (dating). When global life satisfaction questions were presented before dating questions, the answers were not correlated. However, when items were presented in a reversed order (focusing participants' attention on their dating life first), the correlation was significantly higher.

Smith et al. (2006) conducted a survey among Parkinson's disease patients. Half of the participants were told that the survey was conducted by a regional medical center and its topic was related to Parkinson's disease. The other group of participants was asked to participate in a general population survey conducted by the university, assessing quality of life and happiness. Result showed the correlation between general life satisfaction and specific health satisfaction was high for the participants who were told that the survey focused on Parkinson's disease patients. When both groups were presented with specific health-related questions first, the correlation was high regardless of the introduction. This indicated that introductory information and specific questions can prime answers for general questions regarding well-being.

\section{Body Satisfaction and Life Satisfaction}

Body satisfaction depends on several factors such as social influences (Sheldon 2010), physical activity (Umstattd et al. 2011), and body weight (Sira and White 2010). It is noteworthy that body satisfaction also differs across men and women, e.g. among women body dissatisfaction rises with body weight, but while overweight men also wish to be thinner, normal and underweight men wish for a larger physique (Phillips and de Man 2010). Furthermore, body dissatisfaction is common among both women and men and is especially prominent in women who perceive themselves to be under family and peer pressure to have 'perfect' bodies (Sheldon 2010).

Body satisfaction is a significant aspect of well-being, as it can influence interpersonal relations (Forand et al. 2010). Muñoz and Ferguson (2012) showed a link between women's body satisfaction and satisfaction with life in general. Body satisfaction proved to be a stronger predictor of life satisfaction than depression, parental affection, female competition and television exposure to ideal body models. Yet, along the lines of focusing illusion, we can assume that people moderately satisfied or dissatisfied with their body have many daily experiences unrelated to their physical appearance. Once they stop focusing on their body they tend to think about other everyday matters.

Given this empirical evidence and theoretical rationale, it is imperative to test to the extent to which the relationship between body satisfaction and overall life satisfaction is enhanced when individuals are explicitly focused on body satisfaction. Individuals from non-clinical populations who are dissatisfied with their body may perceive most daily experiences as being unrelated to their physical appearance. They do not evaluate their daily routines in relation to body satisfaction unless something particular draws their attention to their body appearance.

\section{The Present Study}

Based on prior work on the focusing illusion (Smith et al. 2006), we predicted that the relationship between body satisfaction and life satisfaction would be stronger for individuals focused on their body compared to individuals with no specific focus. This hypothesis is based on the focusing illusion theory, which stipulates that individuals focused on one aspect of life 
tend to overestimate its impact on their overall satisfaction with life (Schkade and Kahneman 1998). More specifically, when body satisfaction is measured before life satisfaction the relationship between body satisfaction and life satisfaction will be stronger than with the reversed order, i.e. the correlation between body satisfaction and life satisfaction would be moderated by the order of the administration of scales measuring both constructs. In testing this hypothesis, we controlled for gender as body satisfaction differs between women and men (Phillips and de Man 2010; Rysst and Klepp 2010).

\section{Method}

\subsection{Participants}

The study involved 97 student volunteers (71.1\% women) aged between 19 and 36 years $(M=21.85, S D=2.74)$. Groups of students were approached before classes by experimenters and invited to a psychological study. Four participants were excluded as outliers: three with body satisfaction and one with life satisfaction scores two standard deviations below the mean. Consequently, there were 33 women and 14 men in the 'body focus' group and 32 women and 14 men in the 'no focus' group. The study was conducted in accordance with guidelines provided by Institutional Ethics Committee. Participation in the study was strictly voluntary and each participant signed an informed consent. Participants received no incentives for taking part in this study.

\subsection{Measures}

We used the 5-item Satisfaction with Life Scale (SWLS; Diener et al. 1985) to measure global cognitive judgments of one's life. The SWLS includes items such as 'The conditions of my life are excellent'. The answering scale ranges from 1 'strongly disagree' to 7 'strongly agree' $(\alpha=.82)$. The maximum score was 34 for this scale.

We also used the Body Satisfaction Scale (BSS; Neumark-Sztainer et al. 2004), which assesses satisfaction with height, weight, body shape, waist, hips, thighs, stomach, face, body build, and shoulders. The scale contains 12 items, which are rated on a 5-point Likerttype scale, ranging from 1 'strong dissatisfaction' to 5 'strong satisfaction', $(\alpha=.88)$. The maximum score was 41 in the present sample.

\subsection{Procedure}

Both questionnaires were placed in separate envelopes. Participants were randomized to first complete the SWLS questionnaire ('no focus' group, $\mathrm{n}=48$ ) or the BSS ('body focus' group, $n=49$ ). The respective questionnaires were in an envelope marked with letter A. The remaining scale was in envelope B. Participants were asked to complete the questionnaire from envelope A first and place it back into the envelope followed by completing envelope B containing the remaining scale.

\subsection{Statistical Analysis}

Using ordinary least squares regression, we regressed satisfaction with life on body satisfaction, gender $(0=$ women, $1=$ men $)$, a binary variable representing the order of the 
scales ( $0=$ life satisfaction first; $1=$ body satisfaction first), and two interaction terms: 1 . body satisfaction $\times$ scale order and 2 . body satisfaction $\times$ gender. Prior to hypothesis testing we performed Kolmogorov-Smirnov tests for normality with non-significant differences indicating the normal distribution of scores. For descriptive purposes we present $r$-Pearson correlations. Moderations were tested with a PROCESS computational tool (Hayes 2013) operating within IBM SPSS 21 statistical package that was also used for the remaining statistical analyses.

\section{Results}

Descriptive statistics and inter-correlations between study variables are presented in Table 1. On average, participants were satisfied with their life and moderately satisfied with their body. Non-significant Kolmogorov-Smirnov tests for normality indicated that scores were normally distributed for body satisfaction, $K-S(93)=0.07, p>.05$, and for life satisfaction, $K-S(93)=0.06, p>.05$. The Pearson's $r$ correlation between body satisfaction and life satisfaction was $r=.16, p>.05$ for the 'no focus' condition and $r=.48, p<.001$ for the focusing condition.

The results indicated that individuals who were more satisfied with their body were also more satisfied with their life, as indicated by a main effect of body satisfaction on life satisfaction (Table 2). Furthermore, a significant interaction term (body satisfaction $\times$ scale order) revealed that satisfaction with body had a stronger effect on life when

Table 1 Descriptive statistics and inter-correlations among study variables

Scales order coded as

$0=$ satisfaction with life first,

$1=$ satisfaction with body first. gender coded as $0=$ woman, $1=$ men

$* p<.05 ; * * p<.01$

\begin{tabular}{llll}
\hline & 1 & 2 & 3 \\
\hline 1. Satisfaction with body & & & \\
2. Satisfaction with life & $.35^{* *}$ & & \\
3. Age & .16 & -.07 & \\
4. Gender & .19 & -.03 & $.36^{* * *}$ \\
5. Scales order & .14 & .18 & -.09 \\
$M$ & 3.56 & 4.24 & 21.85 \\
$S D$ & 0.56 & 1.05 & 2.79 \\
Min. & 1.92 & 1.6 & 19 \\
Max. & 4.67 & 6.8 & 36 \\
\hline
\end{tabular}

Table 2 Determinants of life satisfaction

\begin{tabular}{lcccc}
\hline & $b$ & SE $b$ & $t$ & $p$ \\
\hline Body satisfaction & .39 & .11 & 3.53 & $<.001$ \\
Scale order & .25 & .19 & 1.31 & n.s. \\
Gender & -.20 & .21 & -.94 & n.s. \\
Body satisfaction $\times$ Scale order & .43 & .22 & 1.99 & $<.05$ \\
Body satisfaction $\times$ Gender & -.08 & .22 & -.35 & n.s. \\
\hline
\end{tabular}

Scale order coded as $0=$ satisfaction with life first, $1=$ satisfaction with body first. Gender coded as $0=$ woman, $1=$ men 


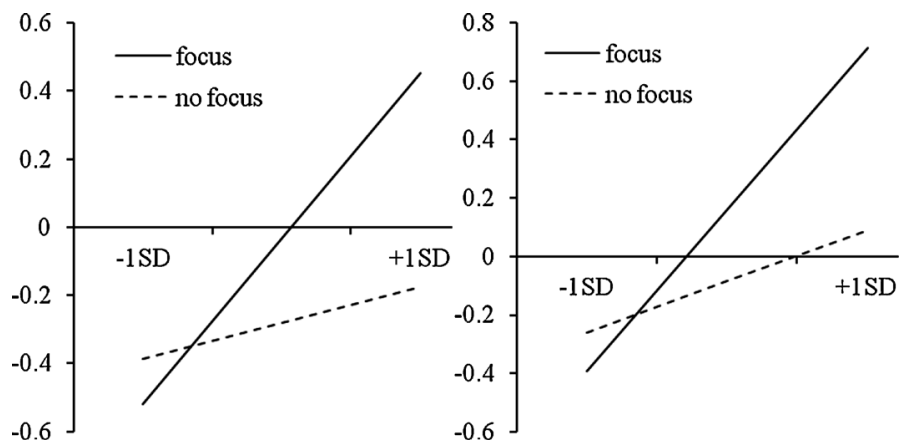

Fig. 1 Relationship between body satisfaction and satisfaction with life depending on focus (i.e. the order of scales administration) in men (left) and women (right)

individuals were asked about body first. This model explained $19 \%$ of the variance in satisfaction with life, $R^{2}=.188, F(5,87)=4.05, p<.01$ The interaction explained additional $3.7 \%$ of the variance in satisfaction in life, $\Delta R^{2}=.037, F(1,87)=3.97$, $p<.05$. The interaction of body satisfaction with gender was not significant and did not explain any additional amount of variance in satisfaction with life, $\Delta R^{2}=.001, F(1$, $87)=0.12, p>.05$.

In sum, the interaction of scale order comprised a significant relationship between body satisfaction and life satisfaction when body satisfaction was reported first, $b=.62$, SE $\mathrm{b}=.18, p<.001$ for women and $b=.55$, SE $\mathrm{b}=.19, p<.01$ for men, and a nonsignificant relationship when participants were asked about their life first, $b=.19$, SE $\mathrm{b}=.16, p=.25$ for women, and $b=.12, \mathrm{SE} \mathrm{b}=.21, p=.58$ for men (see Fig. 1).

\section{Discussion}

The present study examined whether overall body satisfaction is prone to the focusing illusion. We tested if a temporal (experimentally induced) evaluative focus on body can influence judgments about one's overall satisfaction with life. Built on prior experimental work where the order of satisfaction measures was manipulated resulting in the focusing illusion (Strack et al. 1988), we randomized participants to different conditions asking questions about either the body or about life first. In line with predictions, individuals satisfied with their body were more likely to report higher satisfaction with life when they were asked about their body satisfaction first. This conditional effect significantly added to a baseline correlation between both domains of satisfaction.

This study documented a partial focusing illusion regarding body satisfaction, i.e. a situation when the baseline correlation is enhanced by an explicit focus on a specific aspect of life. This baseline correlation suggests that body satisfaction is spontaneously taken into consideration while forming judgments about satisfaction with life (Schimmack and Oishi 2005). It demonstrates the validity of self-report life-satisfaction measures, even if manipulations with temporarily accessible information have an influence on responses. However, individuals who were made to focus on their body increasingly relied on body information in their ratings of satisfaction with life, as indicated by an increase in explained variance in satisfaction with life. Similar instances of partial focusing were observed in previous studies (Aknin et al. 2009). 
It is important to identify those aspects of life that people consider significant for their happiness. Focusing attention on aspects of life with which one is satisfied promotes significant, yet often transient, increases in well-being (Emmons and McCullough 2003; Seligman et al. 2005; Toepfer et al. 2012). Furthermore, the literature on positive psychology interventions provides numerous avenues as to how a focus on positive aspects of the future self can result in increased happiness (Layous et al. 2013). A promising study has collected data from a sample of self-selected individuals dissatisfied with their body (Geraghty et al. 2010). A brief psychological intervention aimed at fostering a positive focus was efficacious in reducing body dissatisfaction with effects comparable to elements of cognitive therapy (monitoring and restructuring) but with higher attrition. Further studies might test how focusing illusion could be used to increase well-being of individuals dissatisfied with their body, and how those who are satisfied already can reap additional benefits.

Asking about life satisfaction first and its hypothetical correlates later may promote the identification of those specific aspects of life that may have more enduring effects on overall well-being, such as becoming a spouse or a parent (Kohler et al. 2005). Some problems within the field of well-being research require measures to influence particular mind-set of participants. For instance, the utility of indicators used in national surveys depends on procedures that minimize the unique characteristics of a particular moment (Campbell et al. 1976). The current study provided new experimental evidence that the focusing illusion can be a psychometric problem for studies on satisfaction with life. The order of questionnaires measuring satisfaction is meaningful (Smith et al. 2006). More specifically, starting with questions about specific satisfaction favors identification of these aspects of well-being that can anchor peoples' satisfaction with life in general. Further studies might test which of the several available instruments for the measurement of satisfaction with life are more prone or resistant to the focusing illusion (Cummins et al. 2003; Diener et al. 1985). Moreover, it seems that latent state-trait approaches that allow to separate traits from occasion specific influences might be used to minimize the influences of situational factors and attenuate the measurement of satisfaction from random error due to a temporal focus (Eid and Diener 2004).

Our study may have practical implications. By popularizing images of happy and goodlooking people, the media promotes the belief that one would be lastingly happy if only his or her body were closer to the ideal. This illusion is also pervasive in novels. Kaminski and Magee (2013) showed that reading about protagonists with low body esteem predicted increased weight concerns among college women. Moreover, media influence is a significant predictor of consideration of cosmetic surgery (Swami 2009) and increasing numbers of cosmetic surgeries linked with body image disturbances have been observed (Callaghan et al. 2011). The ideal promoted excessively in media contributes heavily to body image. Internalization of such an ideal is regarded as a risk factor for eating disturbance (Homan 2010).

The limitation of this study may include its moderate sample size, relatively lower number of male participants in the sample, and not accounting for the body mass index of participants. Moreover, satisfaction scores for body and life were normally distributed, with the mean suggesting that the participants were generally satisfied with their life and with their body. Further studies might test if the same pattern of results hold for clinical groups, for instance for those who are dissatisfied with their body or depressed individuals. Furthermore, the approach we used is only one of the validated methods of testing the focusing illusions. Different research paradigms might be used (e.g. longitudinal designs) to provide a more robust and versatile picture of the body focusing illusion. Further 
research could test if the efforts to improve life satisfaction by improving body satisfaction are likely to fulfill the expectations. Moreover, despite the effects of focusing illusion being valid on a group level, there can be meaningful individual differences (random effects) with some individuals more and some individuals less prone to the body satisfaction focusing illusion. Larger sample sizes combined with other statistical analysis methods (e.g. multilevel modeling) might be used to disentangle fixed and random effects of body satisfaction on satisfaction with life. Lastly, more advanced experimental tests might be developed to examine the focusing illusion. In the present study, individuals are randomly assigned to a group where the focus in a given domain is facilitated or to a control group with no specific focus. Stronger evidence for the focusing illusion would be provided if each participant completed two trials. For instance, each participant could complete the measure of life satisfaction and then body satisfaction, and several days after (to avoid memory effects) the same participants could complete the scales in the reversed order. The focusing illusion would be indicated by significant within-subject rather than betweensubject differences. Furthermore, each participant could repeat the same experiment with a broader range of life domains which would overcome a general limitation of current experimental studies on the focusing illusion that examine single life domains (e.g. Smith et al. 2006).

In conclusion, the focusing illusion regarding body satisfaction pertains to the problem of consequences of counterfactual thinking. People can act upon motivations resulting from "what-if" considerations. Some people can engage in strategies to improve their body satisfaction, expecting that these efforts will make them happier, i.e. physical training, dieting or cosmetic surgery. Focusing illusion is a caveat not only for researchers, but also for lay people who try to look better and be happier.

Open Access This article is distributed under the terms of the Creative Commons Attribution License which permits any use, distribution, and reproduction in any medium, provided the original author(s) and the source are credited.

\section{References}

Aknin, L. B., Norton, M. I., \& Dunn, E. W. (2009). From wealth to well-being? Money matters, but less than people think. The Journal of Positive Psychology, 4, 523-527.

Callaghan, G. M., Lopez, A., Wong, L., Northcross, J., \& Anderson, K. R. (2011). Predicting consideration of cosmetic surgery in a college population: A continuum of body image disturbance and the importance of coping strategies. Body Image, 8, 267-274.

Campbell, A., Converse, P. E., \& Rodgers, W. L. (1976). The quality of American life: Perceptions, evaluations, and satisfactions. New York: Russell Sage Foundation.

Cummins, R. A., Eckersley, R., Van Pallant, J., Vugt, J., \& Misajon, R. (2003). Developing a national index of subjective wellbeing: The Australian Unity Wellbeing Index. Social Indicators Research, 64, $159-190$.

Diener, E., Emmons, R. A., Larsen, R. J., \& Griffin, S. (1985). The satisfaction with life scale. Journal of Personality Assessment, 49, 71-75.

Eid, M., \& Diener, E. (2004). Global judgments of subjective well-being: Situational variability and longterm stability. Social Indicators Research, 65, 245-277.

Emmons, R. A., \& McCullough, M. E. (2003). Counting blessings versus burdens: An experimental investigation of gratitude and subjective well-being in daily life. Journal of Personality and Social Psychology, 84, 377-389.

Forand, N. R., Gunthert, K. C., German, R. E., \& Wenze, S. J. (2010). Appearance investment and everyday interpersonal functioning: An experience sampling study. Psychology of Women Quarterly, 34, 380-393. 
Geraghty, A. W., Wood, A. M., \& Hyland, M. E. (2010). Attrition from self-directed interventions: Investigating the relationship between psychological predictors, intervention content and dropout from a body dissatisfaction intervention. Social Science and Medicine, 71, 30-37.

Hawkins, D. N., \& Booth, A. (2005). Unhappily ever after: Effects of long-term, low-quality marriages on well-being. Social Forces, 84, 451-471.

Hayes, A. F. (2013). Mediation, moderation, and conditional process analysis. New York, NY: Guilford.

Homan, K. (2010). Athletic-ideal and thin-ideal internalization as prospective predictors of body dissatisfaction, dieting, and compulsive exercise. Body Image, 7, 240-245.

Judge, T. A., \& Watanabe, S. (1993). Another look at the job satisfaction-life satisfaction relationship. Journal of Applied Psychology, 78, 939-948.

Kahneman, D., Krueger, A. B., Schkade, D., Schwarz, N., \& Stone, A. A. (2006). Would you be happier if you were richer? A focusing illusion. Science, 312, 1908-1910.

Kaminski, M. J., \& Magee, R. G. (2013). Does this book make me look fat? The effect of protagonist body weight and body esteem on female readers' body esteem. Body Image, 10, 255-258.

Kohler, Hans-Peter, Behrman, Jere R., \& Skytthe, Axel. (2005). Partner + children = happiness? An assessment of the effect of fertility and partnerships on subjective well-being in Danish twins. Population and Development Review, 31, 407-445.

Layous, K., Nelson, S. K., \& Lyubomirsky, S. (2013). What is the optimal way to deliver a positive activity intervention? The case of writing about one's best possible selves. Journal of Happiness Studies, 14, $635-654$.

Muñoz, M. E., \& Ferguson, C. J. (2012). Body dissatisfaction correlates with inter-peer competitiveness, not media exposure: A brief report. Journal of Social and Clinical Psychology, 31, 381-392.

Neumark-Sztainer, D., Goeden, C., Story, M., \& Wall, M. (2004). Associations between body satisfaction and physical activity in adolescents: Implications for programs aimed at preventing a broad spectrum of weight-related disorders. Eating Disorders, 12, 125-137.

Oishi, S., Schimmack, U., \& Colcombe, S. J. (2003). The contextual and systematic nature of life satisfaction judgments. Journal of Experimental Social Psychology, 39, 232-247.

Phillips, N., \& de Man, A. F. (2010). Weight status and body image satisfaction in adult men and women. North American Journal of Psychology, 12, 171-184.

Rysst, M., \& Klepp, I. G. (2010). Looking good and judging gazes: The relationship between body ideals, body satisfaction and body practices among Norwegian men and women. Health, 4, 259-267.

Schimmack, U., \& Oishi, S. (2005). The influence of chronically and temporarily accessible information on life satisfaction judgments. Journal of Personality and Social Psychology, 89, 395-406.

Schkade, D. A., \& Kahneman, D. (1998). Does living in California make people happy? A focusing illusion in judgements of life satisfaction. Psychological Science, 9, 340-346.

Schwarz, N., Strack, F., \& Mai, H. P. (1991). Assimilation and contrast effects in part-whole question sequences: A conversational logic analysis. Public Opinion Quarterly, 55, 3-23.

Seligman, M. E. P., Steen, T. A., Park, N., \& Peterson, C. (2005). Positive psychology progress. Empirical validation of interventions. American Psychologist, 60, 410-421.

Sheldon, P. (2010). Pressure to be perfect: Influences on college students' body esteem. Southern Communication Journal, 75, 277-298.

Shin, R. Q., Morgan, M. L., Buhin, L., Truitt, T. J., \& Vera, E. M. (2010). Expanding the discourse on urban youth of color. Cultural Diversity and Ethnic Minority Psychology, 16, 421-426.

Sira, N., \& White, C. P. (2010). Individual and familial correlates of body satisfaction in male and female college students. Journal of American College Health, 58, 507-514.

Smith, D. M., Schwarz, N., Roberts, T. R., \& Ubel, P. A. (2006). Why are you calling me? How study introductions change response patterns. Quality of Life Research, 15, 621-630.

Stokes, R., \& Frederick-Recascino, C. (2003). Women's perceived body image: Relations with personal happiness. Journal of Women and Aging, 15, 17-29.

Strack, F., Martin, L. L., \& Schwarz, N. (1988). Priming and communication: Social determinants of information use in judgments of life satisfaction. European Journal of Social Psychology, 18, 429-442.

Swami, V. (2009). Body appreciation, media influence, and weight status predict consideration of cosmetic surgery among female undergraduates. Body Image, 6, 315-317.

Toepfer, S. M., Cichy, K., \& Peters, P. (2012). Letters of gratitude: Further evidence for author benefits. Journal of Happiness Studies, 13, 187-201.

Umstattd, M. R., Wilcox, S., \& Dowda, M. (2011). Predictors of change in satisfaction with body appearance and body function in mid-life and older adults: Active for Life. Annals of Behavioral Medicine, 41, 342-352. 